\title{
The effects of apomorphine and lithium chloride on the "transport response" in white rats
}

\author{
CHRISTOPHER WILSON \\ Lafayette College, Easton, Pennsylvania
}

(B. H. Cohen, Sponsor)

\begin{abstract}
An experiment was carried out to dissociate the central stimulation effects and the peripheral gastric distress effects of the dopamine agonist apomorphine on the "transport response" in white rats. Forty-day-old rats were administered apomorphine $(10 \mathrm{mg} / \mathrm{kg})$ or lithium choride $(30 \mathrm{mg} / \mathrm{kg})$ or saline, and were then tested for the presence and intensity of the transport response. Compared with saline-administered control rats, those administered apomorphine exhibited a significant increase in response intensity, whereas those administered lithium chloride exhibited no effect.
\end{abstract}

Behavioral activation can be induced with a variety of types of external stimuli. In infant rats, administration of stimuli such as the intraoral infusion of milk (Hall, 1979a) and the tail pinch (Antelman, Rowland, \& Fisher, 1976; Antelman \& Szechtman, 1975; Szechtman \& Hall, 1980) can induce an increase in behavioral arousal, which is thought to be the result of the engagement of endogenous dopamine activity (Camp \& Rudy, 1987). Hall (1979b) reported that levels of behavioral arousal induced by milk infusion varied positively with increasing lengths of maternal deprivation. He reported increases in general activity in 1- to 6-day-old pups and increases in specific behaviors (e.g., probing and mouthing) in 20-day-old pups. We currently are preparing data that indicate that extended, 24-h, maternal deprivation can cause an increase in responsiveness to stimuli that normally elicit some stereotypic responses in infant rats (Wilson, Cromey, \& Kramer, 1988). We became aware that the ability to induce behavioral activation may, in part, be a function of an increase in the stress level, or discomfort level, of the animal.

Brewster and Leon (1980) described a behavior pattern in the infant rat, which enables the mother to transport the pup efficiently from one location to another. This "transport response" is characterized by an active flexion and adduction of the hindlimbs and extension and adduction of the forelimbs and is elicited when the mother attempts to transport the infant by grasping it and suspending it from the nape of the neck. The transport response is an active response that can be potentiated by nonnatural stimuli, such as a puff of air, a spray of water to the ventrum, or a tail pinch (Wilson, 1988). Thus, its physiological properties may be related to those systems that subserve the set of responses associated with behavioral activation. The transport response appears to be subserved by a dopamine system since administration of

Address correspondence to Christopher Wilson, Department of Psychology, Lafayette College, Easton, PA 18042. haloperidol can disrupt the response in 19-day-old rats (Wilson, Cullen, \& Sendell, 1984). Wilson (1985) also showed that administration of apomorphine, an effective dopamine agonist (Anden, Fuxe, Hokfelt, \& Rubenson, 1967; Ernst, 1967), can reinstate the transport response in 40-day-old rats, animals normally too old to show an intense response.

Apomorphine also is a potent emetic and, thus, can cause gastric distress (Gilman, Goodman, \& Gilman, 1980). The question has arisen that perhaps the increase in transport response intensity reported by Wilson (1985) is, in part, a function of gastric distress associated with administration of high levels of apomorphine. The present experiment, in part a replication of the Wilson (1985) study, was designed to assess this possibility. Subjects were given administrations of apomorphine, as in the Wilson (1985) report, or lithium chloride or a saline control solution. Lithium chloride was used in this experiment because it has been shown to be an agent that reliably can induce gastric distress (Nachman \& Hartley, 1975). Following administration of the particular drug regimens, subjects were given two test phases to assess intensity of the transport response. I employed the additional test phase because previous work from this lab (Wilson \& Greenberg, 1986) indicated that, in some cases, giving repeated stimulations to elicit the transport response increased the response intensity. It seemed reasonable that if the transport response were produced by stimulating dopamine systems, then repeated stimulations should result in a successive response increment over trials as these systems are engaged. However, if the increase in transport response intensity caused by apomorphine results from gastric distress, no increments in the apomorphine group from the first to the second test session should occur.

\section{METHOD}

\section{Subjects}

The subjects in this experiment were 66 albino Sprague-Dawley rats, 40 days old at the time of testing. Litters were derived from breeding 
colonies in the department of psychology at Lafayette College. All litters were housed with their mothers in clear Plexiglas breeding cages in a room kept at $22^{\circ} \mathrm{C}$ and on a 12:12-h light:dark cycle with lights on at 0700 . All testing occurred between 1000 and $1200 \mathrm{~h}$, and each rat was tested at only one drug condition.

\section{Materials}

Apomorphine $\mathrm{HCl}$ and lithium chloride were purchased from Sigma Chemical Co., St. Louis, Missouri.

\section{Procedure}

Approximately 1 week prior to parturition, pregnant female rats were placed in clear Plexiglas breeding cages containing nesting material. Each day at 0900 and $1700 \mathrm{~h}$ the cages were checked for the presence of newborn litters, and the first day a litter was present was recorded as Day 0. On postnatal Day 1 each litter was culled to 8 pups; litters containing fewer than 8 pups were not used in this experiment. On the day of testing, postnatal Day 40, the pups were separated from their mothers and placed in breeding cages containing fresh litter. At this point, each pup was given an i.p. administration of apomorphine $(10 \mathrm{mg} / \mathrm{kg} / 5 \mathrm{ml})(n=22)$, an i.p. administration of lithium chloride $(30 \mathrm{mg} / \mathrm{kg} / 5 \mathrm{ml})(n=22)$, or an i.p. administration of saline $(5 \mathrm{ml} / \mathrm{kg})$ $(n=22)$. The animals then were returned to the Plexiglas breeding cage for $20 \mathrm{~min}$, after which they were given three postdrug test trials for the occurrence of the transport response. The tests were identical to those described in previous reports (Wilson, 1985; Wilson et al., 1984): the pup was grasped by the nape of the neck between the experimenter's thumb and first two fingers. The pup's response was graded on a scale of 0-5 according to the schema proposed by Brewster and Leon (1980), in which one point is counted for each forelimb, hindlimb, and/or tail that the animal brings into contact with its ventral surface when it is grasped. Each subject's trials were separated by approximately 1-min intertrial intervals, and the mean of the three trials was used for statistical analyses. Since pups in litters of 8 subjects each were run in succession, actual testing in each test phase took approximately $3 \mathrm{~min}$. Seven minutes after the initial test phase, 30 min after drug administration, the rats were given the second series of three test trials with 1-min intertrial intervals per rat.

\section{RESULTS AND DISCUSSION}

Results for this experiment are presented in Table 1. There appears to be a large increment in transport response intensity between the subjects that received apomorphine and those that were given either saline or lithium chloride. An analysis of variance ${ }^{1}$ (Kirk, 1968) revealed a significant drug effect $[F(2,63)=19.66$, $p<.05]$, a significant trial effect $[F(1,63)=18.79$, $p<.05]$, and a significant drug $\times$ trial interaction $[F(2,63)=5.03, p<.05]$. Scheffé post hoc tests re-

Table 1

Mean Transport Response Intensity and Standard Error as a Function of Drug Condition and Testing Phase

\begin{tabular}{|c|c|c|c|c|}
\hline \multirow[b]{3}{*}{ Drug Condition } & \multicolumn{4}{|c|}{ Response Intensity } \\
\hline & \multicolumn{2}{|c|}{$\begin{array}{c}20-\min \\
\text { Postadministration }\end{array}$} & \multicolumn{2}{|c|}{$\begin{array}{c}\text { 30-min } \\
\text { Postadministration }\end{array}$} \\
\hline & $M$ & $S E$ & $M$ & $S E$ \\
\hline Apomorphine & 1.65 & $.24 *$ & 2.46 & $.28 * \dagger$ \\
\hline Lithium Chloride & 0.53 & .13 & 0.61 & .17 \\
\hline Saline & 0.52 & .15 & 0.86 & $.21 \dagger$ \\
\hline
\end{tabular}

*Reliably different from the saline control condition. †Reliably different from the respective test phase 1. vealed that the transport response intensity for the apomorphine group was significantly greater than that for the lithium chloride group or the saline control group for both the 20-min and 30-min postadministration test trials. Post hoc tests also revealed that the response intensity for the apomorphine group increased significantly from the 20- to the 30-min trial time. There was also an increase in the intensity of the transport response scores from the 20- to the 30-min trial time for the saline control group, even though the response remained very weak for the second test phase in these animals. No other comparisons were reliably different.

It appears from the data that the increase in transport response intensity is caused by the stimulation of dopamine receptors and is not the result of gastric distress produced by the apomorphine. Apomorphine stimulates other forms of stereotypy (Havemann, Magnus, Moller, \& Kuschinsky, 1986; Szechtman, 1986), and particular apomorphine-dependent responses have been associated with specific dopamine-innervated structures (Melzacka, Wisniowska, \& Vetulani, 1978). Work in this laboratory currently is directed toward better identifying ecological factors that both increase and decrease the probability intensity of the transport response and at identifying the neural substrates involved in this complex and ecologically important behavior.

\section{REFERENCES}

Anden, N., Fuxe, K., Hokfelt, T., \&ubenson, A. (1967). Evidence for DA receptor stimulation by apomorphine. Journal of Pharmacy \& Pharmacology, 19, 627-629.

Antelman, S. M., Rowland, N. E., \& Fisher, A. E. (1976). Stimulation bound ingestive behavior: A view from the tail. Physiology \& Behavior, 17, 743-748.

Antelman, S. M., \& Szechtman, H. (1975). Tail pinch induces eating in sated rats which appears to depend on nigrostriatal dopamine. Science, 189, 731-733.

Brewster, J., \& LeON, M. (1980). Facilitation of maternal transport by Norway rat pups. Journal of Comparative \& Physiological Psychology, 94, 80-88.

CAMP, L. L., \&udy, J. W. (1987). Behavioral activation in infant rats: Pharmacological evidence for dopaminergic mediation. Psychobiology, 15, 317-328.

ERNST, A. M. (1967). Mode of action of apomorphine and dexamphetamine on gnawing compulsion in rats. Psychopharmacologia, 10, 316-323.

Gilman, A. G., Goodman, L. S., \& Gilman, A. (Eds.). (1980). Goodman and Gilman's the pharmacological basis of therapeutics (6th ed.). New York: Macmillan.

HALL, W. G. (1979a). Feeding and behavioral activation in infant rats. Science, 205, 206-209.

Hall, W. G. (1979b). The ontogeny of feeding in rats: I. Ingestive and behavioral responses to oral infusions. Journal of Comparative \& Physiological Psychology, 93, 977-1000.

havemann, U., Magnus, B., Moller, H. G., \& Kuschinsky, K. (1986). Individual and morphological differences in the behavioral responses to apomorphine in rats. Psychopharmacology, 90, 40-48.

KIRK, R. E. (1968). Experimental design: Procedures for the behavioral sciences. Belmont, CA: Brooks/Cole.

Melzacka, M., Wisniowska, G., \& Vetulani, J. (1978). The distribution of apomorphine in rat brain: Possible behavioral correlates. Polish Journal of Pharmacology, 30, 335-345. 
Nachman, M., Hartley, P. L. (1975). Role of illness in producing learned taste aversions in rats: A comparison of several rodenticides. Journal of Comparative \& Physiological Psychology, 89, 1010-1018.

Szechtman, H. (1986). Behavior performed at onset of drug action and apomorphine stereotypy. European Joumal of Pharmacology, 121, 49-56.

Szechtman, H., Hall, W. G. (1980). Ontogeny of oral behavior induced by tail pinch and electrical stimulation of the tail in rats. Journal of Comparative \& Physiological Psychology, 94, 436-445.

WILSON, C. (1985). The effects of apomorphine and isoproterenol on the "transport response" in the white rat. International Journal of Developmental Neuroscience, 3, 279-284.

WILSON, C. (1988). The effects of sensory stimulation in inducing or intensifying the "transport response" in white rats. Animal Learning \& Behavior, 16, 83-88.

Wilson, C., Cromey, A. D., \& Kamer, E. (1988). Maternal depri- vation leads to incremental increases in "transport response" potentiation in infant rat pups. Manuscript submitted for publication.

Wilson, C., Cullen, E., \& Sendell, K. (1984). A pharmacologic investigation of the "transport response" in the white rat. Interna tional Journal of Developmental Neuroscience, 2, 323-329.

Wilson, C., * Greenberg, S. (1986). [Increases in "transport response" intensity with repeated stimulation in white rats]. Unpublished raw data.

\section{NOTE}

1. Appropriate nonparametric tests performed on the data were in complete agreement with the parametric results.

(Manuscript received for publication March 14, 1988.) 